\title{
Development and validation of a pre- scoring system for nonspecific low back pain among general population in Guangzhou: a cross-sectional study
}

\author{
Kai Wang ${ }^{1,2}$, Jing-wen Zhang ${ }^{1}$, Shao-xiong Min ${ }^{3}$, Xin-yi Xü ${ }^{3}$ and Sheng-li An ${ }^{1^{*}}$ (D)
}

\begin{abstract}
Background: Nonspecific Low Back Pain (NLBP) is a common disease with a low cure rate and significant impact on the population. This study aimed to develop and validate a pre-scoring system for identifying the risk of suffering from NLBP among the general population in Guangzhou.

Methods: A total of 1439 eligible subjects were surveyed in Guangzhou by stratified random sampling and was divided randomly into the development dataset (69.6\%) and validation dataset (30.4\%) subsequently. Based on the development dataset, potential associated factors (average exercise times weekly, the intensity of daily work, etc.) with NLBP were tested by the sequential logistic regression, and a pre-scoring system was formulated with Sullivan's method and graded afterward. The internal validity of the system was assessed by AUC and calibration plot, and the external validation was performed in the validation dataset.

Results: The prevalence rates of NLBP in the development dataset and the validation dataset were 12.97 and $13.27 \%$, respectively. Age, BMI, average exercise times weekly, gender, educational level, the intensity of daily work, place of residence, monthly income, overall evaluation of health condition and physiology health were identified as significant factors. The total risk score ranged from 0 to 38, which was split into three risk grades: low risk (0 to 18), intermediate risk (19 to 22 ) and high risk (23 to 38). The pre-scoring system had an adequate calibration and a good discriminating ability with bootstrap-corrected AUC equaling 0.861 in the development dataset and 0.821 in the validation dataset.

Conclusions: A pre-scoring system that could help clinicians to assess the risk of NLBP in the general population was validated. Further validation of the system in a new population or prospective cohort study is suggested.
\end{abstract}

Keywords: Non-specific low back pain, Associated factors, Pre-scoring system, General population

\section{Introduction}

Non-specific low back pain (NLBP) is defined as tension, soreness and/or stiffness that exists in the lower back region for which there is not a specific cause of the pain [1-6]. As a severe public health problem in the world for many years, NLBP has an approximate demission rate of 39\% from work and meanwhile it has been one of

\footnotetext{
*Correspondence: as10418@126.com

'Department of Biostatistics, School of Public Health (Guangdong Provincial Key Laboratory of Tropical Disease Research), Southern Medical University, No. 1838 North Guangzhou Avenue, Guangzhou 510515, People's Republic of China

Full list of author information is available at the end of the article
}

the most common reasons for using complementary and alternative medicine [7-10]. The prevalence of NLBP ranges from 10 to $49 \%$ among the population of different ages, and even as much as $60-85 \%$ during an individual's lifetime [11-13].

Literature indicates NLBP attributes to multiple risk factors, which include gender [12], smoking [14], BMI [7] and improper sitting posture [15], etc. More studies show that females have a higher prevalence of LBP across all age groups than males, and postmenopausal women are more susceptible to it than young or middleaged women due to female hormone fluctuation and

(c) The Author(s). 2019 Open Access This article is distributed under the terms of the Creative Commons Attribution 4.0 International License (http://creativecommons.org/licenses/by/4.0/), which permits unrestricted use, distribution, and reproduction in any medium, provided you give appropriate credit to the original author(s) and the source, provide a link to the Creative Commons license, and indicate if changes were made. The Creative Commons Public Domain Dedication waiver (http://creativecommons.org/publicdomain/zero/1.0/) applies to the data made available in this article, unless otherwise stated. 
menstruation [12]. Given lifestyle, sedentariness or longstanding for over $2 \mathrm{~h}$ has been found to increase the likelihood of having NLBP [15]. Clinically, such problems as scoliosis, low back muscle endurance, abnormal trunk mobility, and muscle imbalance are higher risk factors [16-20].

VonKorff and Miglioretti [21] developed a risk score system to identify patients at risk of chronic LBP, which included pain severity degree, interference with usual activities number of other pain and number of days with back pain in the prior 6 months. Hill et al. [22] developed a brief screening tool to identify subgroups of patients for initial treatment in primary care. Janwantanakul et al. [23] built another risk scoring system to identify office workers susceptible to LBP based on a prospective cohort study. However, their findings, along with other literature, are somewhat inconsistent and not validated by external data [23-28]. To our knowledge, no scoring system to identify the general population at risk of NLBP has been comprehensively established. The purpose of the present study was to construct a pre-scoring system to assist health care providers in identifying individuals' potential probability of suffering from NLBP with only several readily available clinical data.

\section{Material and methods}

\section{Source of data}

This field investigation was conducted from August 2013 to May 2014, and a total of 2100 participants were surveyed using a stratified sampling approach. Briefly, in stage 1 , as the Nansha district is newly established and geographically far from the city centre of Guangzhou, we selected the remaining 11 districts in Guangzhou. One community from each district was randomly selected in stage 2. Finally, we randomly selected individuals from the selected communities (age 20-59). And only one participant was selected from every household. The work was approved by the Institutional Review Board at Zhujiang Hospital, Southern Medical University, Guangzhou, China (NO. 2013-BLK-009).

\section{Outcome definition}

The body diagram from the standardised Nordic questionnaire was used to identify the location of low back pain [29]. In the questionnaire, the following questions were for the primary diagnoses of NLBP, "Have you ever been diagnosed with such lumbar diseases as a lumbar disc herniation, lumbar hyperosteogeny, lumbar muscle strain, lumbar degenerative disease or rheumatism?" "Is this the first time for you to suffer from low back pain?" "How long does your low back pain last?" In this study, low back pain lasted for a duration between 6 weeks and 12 months, and confirmed not from lumbar diseases was defined as NLBP [1].

\section{Participants and predictors}

A questionnaire was designed for the survey, in which participants' private information was omitted. All participants were informed consent and voluntary in this survey.

The inclusion criteria were as follows: (1) age between 20 and 59 years, (2) no deformity or asymmetry in the spine or lower limbs, (3) no mutilation, (4) no problems in reading and communication [23].

The exclusion criteria were as follows: (1) ischialgia resulting from lumbar spinal stenosis, a tumour of the spine, etc., (2) reported pregnancy or spinal, intraabdominal or femoral surgery in the past year and (3) musculoskeletal, rheumatic, orthopaedic, somatic or psychiatric disorders $[7,12,30]$.

The researchers were trained in advance to assist the participants in completing the questionnaire, which included demographic, work-related and psychosocial data as well as the presence of NLBP.

The demographic data included birthday, height, weight, gender, nation, educational level, smoking habits, drinking habits, marital status, average exercise times weekly, place of residence and monthly income.

The work-related factors included the type of occupation, main nature of work, the intensity of daily work, job position and exposure or not to any vibration sources at work.

To assess the quality of life, the participants were also asked to complete the Chinese abbreviated version of World Health Organization Quality of Life (WHOQOL-BREF-Chinese)-Brief, which consisted of 26 items in four domains (physiological health, psychological health, social relation health and environmental health) and two general evaluations about the quality of life and health condition.

Pre-survey was conducted three times to correct items and evaluate the reliability and validity of the questionnaire before formal data collection. The content validity of the questionnaire was assessed by six experienced reviewers, including one biostatistician, one epidemiologist, two surgeons, one physician, and one community manager. The Cronbach' $\alpha$ was 0.818 , which displayed an acceptable outcome.

\section{Sample size and missing data}

It was difficult to calculate the sample size for the observational study, especially in multivariable regression model settings. We used the rule of thumb recommended by Peduzzi et al. [31] and Harrell et al. [32], namely, events per variable (EPV) being 10 or higher in our study. If there were about ten significant associated factors with NLBP, a minimum of $100(10 \times 10)$ participants should have the event in the sample. 
Since the data had no more than $2 \%$ missing values, we imputed it with the EM algorithm to assure the stability of the results. All results were based on the imputed complete dataset.

\section{Statistical analysis}

Continuous variables were expressed as Mean \pm S.D., while categorical or ordinal variables were expressed as absolute (n) and relative (\%) frequency. All the subjects were randomly divided into two sets, a development (69.6\%) dataset, and a validation (30.4\%) dataset. Three steps were taken to develop the pre- scoring system based on the development dataset. Firstly, we conducted univariate logistic regression to select possible associated factors with a $P$-value $\leq 0.1$. Then, a backward logistic regression was used to select potential associated factors (demographic and work-related factor) and to construct a basic model. Finally, psychosocial factors, four domains and two general evaluations about quality of life, were evaluated sequentially based on the above basic model. And a risk model was developed sbsequently. The incremental prognostic usefulness of psychosocial factors was evaluated by the integrated

2,100 participants were surveyed between August 2013 and May 2014 in ten selected communities of Guangzhou.

1,953 questionnaires were successfully collected.

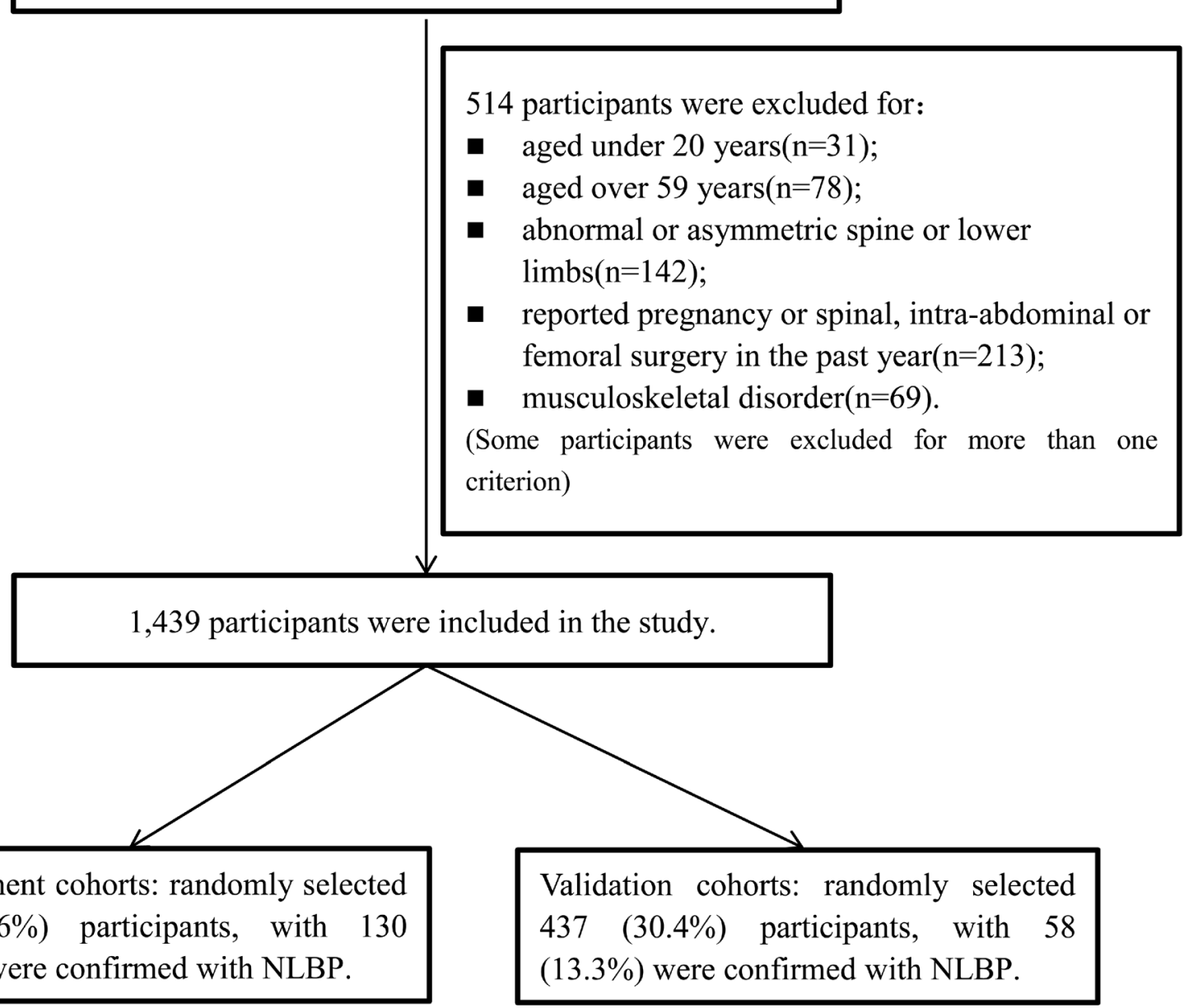

Development cohorts: randomly selected $1,002(69.6 \%)$ participants, with 130 $(13.0 \%)$ were confirmed with NLBP. $(13.3 \%)$ were confirmed with NLBP.

Fig. 1 Flow diagram of enrolling the participants at each stage of study 
Table 1 Baseline characteristics of eligible participants in the development and validation datasets

\begin{tabular}{|c|c|c|c|}
\hline Variable & Whole dataset $(N=1439)$ & Development dataset $(N=1002)$ & Validation dataset $(N=437)$ \\
\hline \multicolumn{4}{|l|}{ Individual characteristics } \\
\hline Age & $34.41 \pm 9.34$ & $34.16 \pm 9.21$ & $34.97 \pm 9.64$ \\
\hline BMl & $21.92 \pm 3.03$ & $21.98 \pm 3.07$ & $21.80 \pm 2.94$ \\
\hline Average exercise times weekly & $2.35 \pm 1.25$ & $2.37 \pm 1.28$ & $2.30 \pm 1.16$ \\
\hline \multicolumn{4}{|l|}{ Gender } \\
\hline Female & $722(50.2)$ & $518(51.7)$ & $204(46.7)$ \\
\hline Male & $717(49.8)$ & $484(48.3)$ & $233(53.3)$ \\
\hline \multicolumn{4}{|l|}{ Educational level } \\
\hline Middle school or below & $228(15.8)$ & $163(16.3)$ & $65(14.9)$ \\
\hline High school & $337(23.4)$ & $233(23.3)$ & $104(23.8)$ \\
\hline College degree or above & $874(60.7)$ & $606(60.5)$ & $268(61.3)$ \\
\hline \multicolumn{4}{|l|}{ Marital status } \\
\hline Singlehood & $417(29.0)$ & $297(29.6)$ & $120(27.5)$ \\
\hline Married & $1001(69.6)$ & $690(68.9)$ & $311(71.2)$ \\
\hline Divorced et al. & $21(1.5)$ & $15(1.5)$ & $6(1.4)$ \\
\hline \multicolumn{4}{|l|}{ Smoking habits } \\
\hline Non-smoking & $1104(76.7)$ & $755(75.3)$ & $349(79.9)$ \\
\hline Smoking & $259(18.0)$ & $195(19.5)$ & $64(14.6)$ \\
\hline No longer smoking & $76(5.3)$ & $52(5.2)$ & $24(5.5)$ \\
\hline \multicolumn{4}{|l|}{ Drinking habits } \\
\hline None & $1032(71.7)$ & $710(70.9)$ & $322(73.7)$ \\
\hline 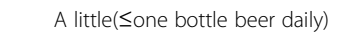 & $346(24.0)$ & $246(24.6)$ & $100(22.9)$ \\
\hline Much(>one bottle beer daily) & $61(4.2)$ & $46(4.6)$ & $15(3.4)$ \\
\hline \multicolumn{4}{|l|}{ Place of residence } \\
\hline City & $334(23.2)$ & $231(23.1)$ & $103(23.6)$ \\
\hline Villages and towns & $717(49.8)$ & $494(49.3)$ & $223(51.0)$ \\
\hline Countryside & $388(27.0)$ & $277(27.6)$ & $111(25.4)$ \\
\hline \multicolumn{4}{|l|}{ Monthly income (CNY) } \\
\hline$<1000$ & $134(9.3)$ & $100(10.0)$ & $34(7.8)$ \\
\hline $1000 \leq<5000$ & $1006(69.9)$ & $702(70.1)$ & $304(69.6)$ \\
\hline $5000 \leq<10,000$ & $258(17.9)$ & $176(17.6)$ & $82(18.8)$ \\
\hline$\geq 10,000$ & $41(2.8)$ & $24(2.4)$ & $17(3.9)$ \\
\hline \multicolumn{4}{|l|}{ Work-related characteristics } \\
\hline \multicolumn{4}{|l|}{ Main nature of work } \\
\hline Brain & $460(32.0)$ & $328(32.7)$ & $132(30.2)$ \\
\hline Brain \& manual & $739(51.4)$ & $506(50.5)$ & $233(53.3)$ \\
\hline Manual & $240(16.7)$ & $168(16.8)$ & $72(16.5)$ \\
\hline \multicolumn{4}{|l|}{ The intensity of daily work } \\
\hline Almost not & $321(22.3)$ & $219(21.9)$ & $102(23.3)$ \\
\hline Light & $765(53.2)$ & $537(53.6)$ & $228(52.2)$ \\
\hline Intergrade & $310(21.5)$ & $219(21.9)$ & $91(20.8)$ \\
\hline Heavy & $43(3.0)$ & $27(2.7)$ & $16(3.7)$ \\
\hline \multicolumn{4}{|l|}{ Vibration } \\
\hline Systemic & $43(3.0)$ & $31(3.1)$ & $12(2.7)$ \\
\hline Partial & $292(20.3)$ & $199(19.9)$ & $93(21.3)$ \\
\hline None & $1104(76.7)$ & $772(77.0)$ & $332(76.0)$ \\
\hline \multicolumn{4}{|l|}{ Psychosocial characteristics } \\
\hline SF1 & $3.24 \pm 0.64$ & $3.23 \pm 0.65$ & $3.28 \pm 0.61$ \\
\hline SF2 & $3.19 \pm 0.76$ & $3.18 \pm 0.76$ & $3.22 \pm 0.75$ \\
\hline SF_PHYS & $15.24 \pm 2.00$ & $15.20 \pm 2.03$ & $15.31 \pm 1.94$ \\
\hline
\end{tabular}


Table 1 Baseline characteristics of eligible participants in the development and validation datasets (Continued)

\begin{tabular}{llll}
\hline Variable & Whole dataset $(N=1439)$ & Development dataset $(N=1002)$ & Validation dataset $(N=437)$ \\
\hline SF_PSYCH & $13.85 \pm 2.21$ & $13.77 \pm 2.26$ & $14.03 \pm 2.09$ \\
SF_SOCIL & $14.21 \pm 2.34$ & $14.24 \pm 2.35$ & $14.15 \pm 2.31$ \\
SF_ENVIR & $12.46 \pm 2.20$ & $12.45 \pm 2.22$ & $12.47 \pm 2.14$
\end{tabular}

Age, years; BMI Body mass index; Vibration means whether or not contacting vibration sources at work. Systemic includes feet or hip contact, and partial means hands contact; SF1 Overall evaluation about quality of life, SF2 Overall evaluation about health condition, SF_PHYS Physiology health domain, SF_PSYCH Psychological health domain, SF_SOCIL Social relation health domain, SF_ENVIR Environmental health domain

discrimination improvement (IDI) and the continuous net reclassification improvement (NRI) [33].

Based on the developed risk model, we created a simple pre-scoring system subsequently by Sullivan et al.'s method [34]. Firstly, we classified the continuous variables into categories in terms of clinical significance. Secondly, we specified the mid-point value as the reference value for each category. To determine the reference values for the first and last categories of continuous variables, we use the 1st and the 99th percentile to minimize the influence of extreme values. Thirdly, the lowest risk category of each variable was served as the base category. The difference of reference values between each category and base category multiplied by the regression coefficient of the corresponding variable in the risk model was defined as the distance of each category from the base category. Fourthly, One score of the scoring system was defined as a constant of 0.48 which means the increase of risk associated with a 5-year increase in age $(0.096 \times 5)$. Finally, the base category of each variable was assigned 0 scores. And the score of other categories was computed by dividing corresponding distance with the constant of 0.48 and then rounded to the nearest integer.

The score was then summed to create a total risk score for each participant, and the participants were classified into three grades: low risk, intermediate risk, and high risk of NLBP.

The discrimination of the models and the system were measured by Areas Under the ROC Curve (AUC). Calibration of predictions was assessed by the calibration plot. The internal validity of the system was assessed by bootstrap techniques, and the external validation was performed in the validation dataset.

If the correlation coefficient between variables was $\geq 0.60$, only the variable judged to be more clinically relevant was included in the model. Confirmatory factor analysis was conducted to recheck the structure validity of the WHO-QOL-BREF-Chinese. All statistical calculations were performed on SAS software (v. 9.3; SAS Institute Inc., Cary, NC). A 2-tailed $P$ value $<0.05$ was considered as statistically significant.

The reporting of the present study closely follows the Transparent Reporting of a multivariable prediction model for Individual Prognosis Or Diagnosis (TRIPOD) statement [35].

\section{Results}

\section{Characteristics of the participants}

The flow chart of participants is presented in Fig. 1. Totally, 2100 questionnaires were distributed and a total of 1953 ones were successfully collected, with a response rate of $93.0 \%$. Among them, 514 were excluded, including 31 aged under 20 years, 78 aged over 59 years, 142 with abnormal or asymmetric spine or lower limbs, 213 reported pregnancies or spinal, intra-abdominal or femoral surgery in the past year and 69 with a musculoskeletal disorder. The final sample covered 1439 participants, 1002 (69.6\%) and 437 (30.4\%) of whom were assigned to the development and validity datasets, respectively. Totally 188 (13.1\%) were confirmed with NLBP, with 130 (13.0\%) in the development dataset and $58(13.3 \%)$ in the validation dataset. The participants aged $34.41 \pm 9.34$ years on average; their body mass index (BMI) was $21.92 \pm 3.03$, and 717 (50.0\%) of them were female. More detailed baseline characteristics of the eligible participants for both the development and validation datasets are shown in Table 1.

\section{NLBP risk model}

The demographic and work-related factors significantly associated with NLBP in the basic model were as follows: age, BMI, average exercise times weekly, gender, educational level, the intensity of daily work, place of residence and monthly income (Table 2). The AUC of the basic model was 0.838 (95\% CI: 0.798-0.878). Two psychosocial factors (the overall evaluation of health condition and physiological health) were added to the final risk model. The risk model had an excellent discriminating power with an AUC of 0.868 (95\%CI: $0.830-0.905)$ and was significantly more effective than the basic model (0.868 vs $0.838, P<0.001)$. Neither co-linearity nor interaction effects were significant.

\section{NLBP pre-scoring system and risk category}

The associated factors and corresponding scores for calculating the risk score of NLBP are presented in Table 3. 
Table 2 Univariate and multivariate logistic regression analysis of NLBP (Development dataset, $N=1002$ )

\begin{tabular}{|c|c|c|c|c|c|c|c|}
\hline \multirow[t]{2}{*}{ Variable } & \multicolumn{2}{|l|}{ Univariate Analysis } & \multicolumn{2}{|l|}{ Basic model } & \multicolumn{3}{|l|}{ Risk model } \\
\hline & $O R(95 \% C l)$ & $P$ & $O R(95 \% C l)$ & $P$ & Coefficient & $O R(95 \% C l)$ & $P$ \\
\hline Age (years) & $1.08(1.06-1.11)$ & $<0.001$ & $1.10(1.07-1.13)$ & $<0.001$ & 0.096 & $1.10(1.07-1.13)$ & $<0.001$ \\
\hline $\mathrm{BMI}\left(\mathrm{kg} / \mathrm{m}^{2}\right)$ & $1.18(1.11-1.24)$ & $<0.001$ & $1.16(1.09-1.25)$ & $<0.001$ & 0.143 & $1.15(1.07-1.24)$ & $<0.001$ \\
\hline Average exercise times weekly & $0.82(0.70-0.97)$ & 0.019 & $0.69(0.57-0.83)$ & $<0.001$ & -0.280 & $0.76(0.62-0.92)$ & 0.006 \\
\hline Female & $1.39(0.96-2.01)$ & 0.084 & $1.75(1.08-2.83)$ & 0.024 & 0.584 & $1.79(1.07-2.99)$ & 0.026 \\
\hline Educational level & & $<0.001$ & & $<0.001$ & & & $<0.001$ \\
\hline Middle school or below & 1.00 & & 1.00 & & 0.000 & 1.00 & \\
\hline High school & $0.99(0.46-2.13)$ & 0.980 & $2.80(1.16-6.74)$ & 0.022 & 0.820 & $2.27(0.90-5.72)$ & 0.082 \\
\hline College degree or above & $2.52(1.35-4.70)$ & 0.004 & $8.11(3.73-17.60)$ & $<0.001$ & 1.906 & $6.72(2.97-15.21)$ & $<0.001$ \\
\hline Marital status & & $<0.001$ & & & & & \\
\hline Singlehood & 1.00 & & & & & & \\
\hline Married & $5.09(2.70-9.61)$ & $<0.001$ & & & & & \\
\hline Divorced et al. & $17.33(5.24-57.30)$ & $<0.001$ & & & & & \\
\hline The intensity of daily work & & $<0.001$ & & $<0.001$ & & & $<0.001$ \\
\hline Almost not & 1.00 & & 1.00 & & 0.000 & 1.00 & \\
\hline Light & $3.18(1.61-6.30)$ & 0.001 & $2.59(1.24-5.42)$ & 0.012 & 0.723 & $2.06(0.96-4.45)$ & 0.065 \\
\hline Intergrade & $5.11(2.49-10.46)$ & $<0.001$ & $5.50(2.47-12.24)$ & $<0.001$ & 1.342 & $3.83(1.68-8.72)$ & 0.001 \\
\hline Heavy & $5.97(1.97-18.07)$ & 0.002 & $22.30(5.87-84.62)$ & $<0.001$ & 2.633 & $13.92(3.36-57.72)$ & $<0.001$ \\
\hline Place of residence & & $<0.001$ & & 0.003 & & & 0.035 \\
\hline City & 1.00 & & 1.00 & & 0.000 & 1.00 & \\
\hline Villages and towns & $3.34(1.82-6.13)$ & $<0.001$ & $3.12(1.53-6.38)$ & 0.002 & 0.870 & $2.39(1.14-5.00)$ & 0.021 \\
\hline Countryside & $2.43(1.25-4.70)$ & 0.009 & $1.83(0.82-4.11)$ & 0.140 & 0.438 & $1.55(0.67-3.59)$ & 0.307 \\
\hline Monthly income (CNY) & & 0.016 & & 0.032 & & & 0.009 \\
\hline$<1000$ & 1.00 & & 1.00 & & 0.000 & 1.00 & \\
\hline $1000 \leq<5000$ & $5.25(1.63-16.88)$ & 0.005 & $2.69(0.77-9.37)$ & 0.119 & 1.145 & $3.14(0.85-11.58)$ & 0.085 \\
\hline $5000 \leq<10,000$ & $4.86(1.42-16.62)$ & 0.012 & $1.82(0.45-7.34)$ & 0.400 & 0.901 & $2.46(0.56-10.82)$ & 0.233 \\
\hline$\geq 10,000$ & $10.78(2.47-47.08)$ & 0.002 & $8.46(1.62-44.33)$ & 0.011 & 2.744 & $15.55(2.71-89.08)$ & 0.002 \\
\hline Main nature of work & & 0.036 & & & & & \\
\hline Brain & 1.00 & & & & & & \\
\hline Brain \& manual & $1.20(0.80-1.81)$ & 0.370 & & & & & \\
\hline Manual & $0.52(0.27-1.02)$ & 0.059 & & & & & \\
\hline Vibration & & 0.013 & & & & & \\
\hline Systemic & 1.00 & & & & & & \\
\hline Partial & $0.36(0.12-1.10)$ & 0.074 & & & & & \\
\hline None & $0.88(0.33-2.35)$ & 0.802 & & & & & \\
\hline Smoking habits & & 0.397 & & & & & \\
\hline Non-smoking & 1.00 & & & & & & \\
\hline Smoking & $1.22(0.80-1.86)$ & 0.350 & & & & & \\
\hline No longer smoking & $2.37(0.47-11.93)$ & 0.294 & & & & & \\
\hline Drinking habits & & 0.881 & & & & & \\
\hline None & 1.00 & & & & & & \\
\hline A little(Sone bottle beer daily) & $0.95(0.61-1.46)$ & 0.798 & & & & & \\
\hline Much(>one bottle beer daily) & $0.80(0.31-2.07)$ & 0.645 & & & & & \\
\hline SF1 & $0.45(0.34-0.61)$ & $<0.001$ & & & & & \\
\hline
\end{tabular}


Table 2 Univariate and multivariate logistic regression analysis of NLBP (Development dataset, $N=1002$ ) (Continued)

\begin{tabular}{|c|c|c|c|c|c|c|c|}
\hline \multirow[t]{2}{*}{ Variable } & \multicolumn{2}{|c|}{ Univariate Analysis } & \multicolumn{2}{|c|}{ Basic model } & \multicolumn{3}{|l|}{ Risk model } \\
\hline & $O R(95 \% C l)$ & $P$ & $O R(95 \% C l)$ & $P$ & Coefficient & $O R(95 \% C l)$ & $P$ \\
\hline SF2 & $0.32(0.24-0.42)$ & $<0.001$ & & & -0.741 & $0.48(0.33-0.69)$ & $<0.001$ \\
\hline SF_PHYS & $0.68(0.61-0.75)$ & $<0.001$ & & & -0.258 & $0.77(0.68-0.88)$ & $<0.001$ \\
\hline SF_PSYCH & $0.78(0.72-0.85)$ & $<0.001$ & & & & & \\
\hline SF_SOCIL & $0.88(0.81-0.95)$ & 0.001 & & & & & \\
\hline SF_ENVIR & $0.86(0.79-0.93)$ & $<0.001$ & & & & & \\
\hline
\end{tabular}

OR Odds ratio, $C I$ Confidence interval, $B M I$ Body mass index, Vibration means whether or not contacting vibration sources at work. Systemic includes feet or hip contact, and partial means hands contact; SF1 Overall evaluation about quality of life, SF2 Overall evaluation about health condition, SF_PHYS Physiology health domain, SF_PSYCH Psychological health domain, SF_SOCIL Social relation health domain, SF_ENVIR Environmental health domain, Basic model includes demographic and work-related factors; Risk model, basic model+SF2+ SF_PHYS

The estimated probability, according to the proposed risk score, was expressed as:

$$
P(\mathrm{NLBP})=\frac{1}{1+e^{-(-11.194+0.48 *(\text { total scores }))}}
$$

where -11.194 and 0.48 were the intercept and slope coefficient from the model, respectively. The risk of NLBP was calculated based on the total score, ranging from 0 to 38, with corresponding predicted probabilities from 0.0 to $99.9 \%$ (Table 4 ). The bootstrap-corrected AUC of the pre-scoring system was 0.861 (95\%CI: 0.822-0.898).

In the validation dataset, the AUC of the system was 0.821 (95\% CI: 0.758-0.883). The receiver operating characteristics curves (ROCs) of the basic model, the risk model, and the system are shown in Fig. 2. The calibration plots of both datasets appeared no apparent overor under-estimation (Fig. 3).

To illustrate the application of the risk score, consider a 30-year-old man with a height of $1.75 \mathrm{~m}$, weight of $70.0 \mathrm{~kg}$, average exercise times weekly of 2 , education level of college degree or above, the intensity of daily work of intergrade, place of residence of urban, monthly income of $>10,000$ RMB, overall evaluation about health condition of satisfied (SF2, 4 score), and physiology health of 14 score (ranging from 5 to 20 score). His total risk score is:

0 (Gender) +2 (Age) +1 (BMI) +2 (Average exercise times weekly) +4 (Educational level) +3 (the intensity of daily work) +0 (Place of residence) +6 (Monthly income $)+0($ SF2 $)+2($ SF_PHYS $)=20$ from Table 3 , and the estimated predicted probability that he has NLBP is $16.88 \%$ according to Formula 1 . We also provided a convenient Excel tool for individuals to acquire the underlying risk of NLBP by entering their personal information (Additional file 1: Excel S1).

We created three NLBP risk categories: low risk ( 0 to 18 scores), intermediate risk (19 to 22 scores), and high risk (23 to 38 scores), to enhance the practical utility of the system. The categories were created by identifying the groups of scores that resulted in "significant" ( $p$ value $<0.001)$ differences in the prevalence rate of NLBP between pairwise categories. The possibilities of developing NLBP in three categories in the development dataset were $4.3,14.8$, and $67.3 \%$, respectively. The corresponding results in the validation dataset were 5.0, 15.5, and $66.7 \%$, respectively (Table 5 ).

\section{Discussion \\ Main finding}

The prevalence rate of NLBP in our study was $13.1 \%$, which is consistent with the findings of $10.0-49.0 \%$ in literature according to the definition of NLBP $[5,11-13$, 36]. The validated pre-scoring system we developed based on ten factors had a high discriminative power at the bootstrap-corrected AUC of 0.861 and was strongly supported by the external validation (AUC of 0.821). These factors were age, BMI, average exercise times weekly, gender, educational level, the intensity of daily work, place of residence, monthly income, overall evaluation of health condition and physiology health. To our knowledge, this is the first simple and validated prescoring system for identifying the risk of NLBP among the general population. An excel evaluation tool was in the Additional file 1.

\section{Interpretation}

Many cohort studies and meta-analyses have been conducted to explore the potential risk factors of NLBP, and the effects of some interventions have been confirmed by well-designed randomised control trials [37]. However, few of them focus on the readily available psychosocial data. In this research, we have not only studied demographic and work-related characteristics, but also concentrate on the psychosocial features. The results show that the overall evaluation of health condition $(O R=0.48)$ and physiology health $(O R=0.77)$ are two unneglectable 
Table 3 Scores of the associated factors in the pre-scoring system

\begin{tabular}{lll}
\hline Associated factor & Category & Scor \\
\hline Age (years) & & 0 \\
& $20 \leq<30$ & 2 \\
& $30 \leq<40$ \\
& $40 \leq<50$ & 4 \\
& $50 \leq<60$ & 6
\end{tabular}

BMI $\left(\mathrm{kg} / \mathrm{m}^{2}\right)$

$<18.5$

$18.5 \leq<24.0$

$24.0 \leq<28.0$

$\geq 28.0$

Average exercise times weekly

$0 \leq \leq 1$

$2 \leq \leq 3$

$\geq 4$

Gender

Male

female

Educational level

middle school or below

high school

college degree or above

The intensity of daily work

$\begin{array}{ll}\text { almost not } & 0 \\ \text { light } & 2 \\ \text { intergrade } & 3 \\ \text { heavy } & 5\end{array}$

Place of residence

city

villages and towns

countryside

Monthly income (CNY)

$<1000$

$1000 \leq<5000$

$5000 \leq<10,000$

$\geq 10,000$

SF2

$\begin{array}{ll}1 \leq \leq 2 & 5 \\ 3 & 2 \\ 4 \leq \leq 5 & 0\end{array}$

SF_PHYS
Score

0

4

Score

AUC for single factor $0.698(0.651-0.746)$

$0.645(0.594-0.696)$

0

1

2

$0.581(0.531-0.632)$

2

1

0

$0.541(0.488-0.594)$

0

1

0.599 (0.550-0.648)

0

2

4

$0.621(0.572-0.670)$

3

5

$0.599(0.550-0.647)$

0

2

1

$0.555(0.504-0.605)$

0

2

4

6

$0.722(0.675-0.769)$

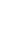

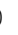

$0.682(0.635-0.729)$

$5 \leq<11$
$11 \leq<14$
$14 \leq<17$
$17 \leq \leq 20$


Table 4 The total score and corresponding risk probability of NLBP

\begin{tabular}{llll}
\hline Total score & Risk probability (\%) & Total score & Risk probability (\%) \\
\hline$<14$ & $<1.0$ & 23 & 46.2 \\
14 & 1.1 & 24 & 58.1 \\
15 & 1.8 & 25 & 69.1 \\
16 & 2.9 & 26 & 78.3 \\
17 & 4.6 & 27 & 85.4 \\
18 & 7.2 & 28 & 90.4 \\
19 & 11.2 & 29 & 93.9 \\
20 & 16.9 & 30 & 96.1 \\
21 & 24.7 & $>30$ & $>97.6$ \\
22 & 34.7 & & \\
\hline
\end{tabular}

factors. It indicates that the risk of NLBP may be reduced by alleviating the stress and tension and keeping optimistic.

Contrary to the results from the majority of literature, our findings show that the higher the income, the higher the risk of NLBP and so it is with the educational level. In our consideration, it may depict a picture in China context where the better-educated cohort is more likely to have access to a higher-income and more prone to being sedentary in the office. The realistic situation is that the cohort of higher-income tends to drive to work or travel, which keeps the waist muscles consistently in a

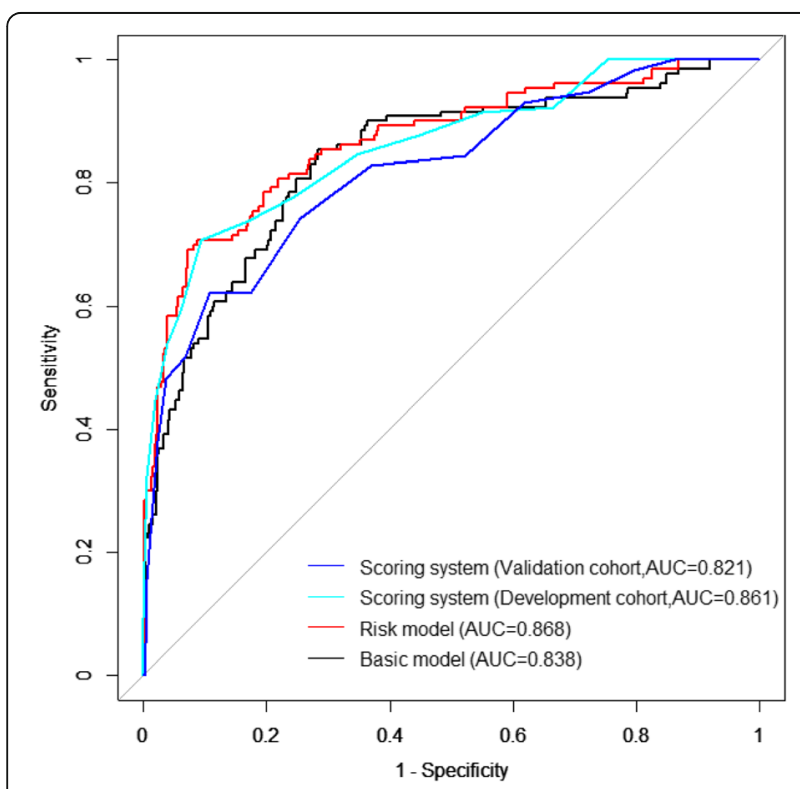

Fig. 2 Receiver operator characteristic curve showing area under the curve for NLBP in general population (Notes: The basic model includes demographical and work-related factors. Risk model means basic model+SF2+SF_PHYS. Scoring system means the sum of each factor score) state of intense stress. Yue et al. [38] pointed out that prolonged sitting and static posture are two potential risk factors of NLBP in China. Cocker et al. [39] and Hadgraft et al. [40] found that more occupational sitting is associated with higher income and education level in Australia. Other literature also gave a similar conclusion about the relation between NLBP and education in our findings [38, 41-46]. On the other side, the cohort of lower income cannot afford a car and therefore tends to go out on a walk or by bicycle. Although they are more likely to be exposed to vibration while working, the influence may be undermined by those mentioned above two significant factors. As it is seen, in the meantime, both the cohort of higher income and higher education, are consistent in doing physical exercises all through the communities in the developed world.

Some researchers have used different statistical models to predict the development of NLBP [23-25, 30], such as Classification Tree Model, Artificial Neural Network, Bayesian method, et al. Their outcomes are moderate and not validated by external population. The logistic regression model owns pretty well stability and easy-tounderstand results, especially in medical research, so we use it in our study. A few researchers in their highly cited papers use different weighted methods based on regression coefficients to develop risk scores [47, 48]. In our research, we chose Sullivan's approach, a generally accepted score construction method, to develop the scoring system, which will make it more stable [34].

\section{Clinical and decision-making implication}

The present study derived and validated a prescoring system rather than a decision rule. It is to provide information that allows clinicians and patients to understand risks faced by patients, and then take actions to reduce the risk of NLBP. The factors incorporated in the constructed pre-scoring system are readily accessible data in general clinical work. The proposed system may help clinicians to identify patients at low risk of NLBP quickly. And among patients with a high risk of NLBP, a more detailed assessment of pain and a diagnostic test would then be needed to quantify the risk of NLBP adequately. Therefore, stratification of the risk level of NLBP patients according to the pre-scoring system is clinically relevant, particularly in disease prevention or care setting where efficient assessment is essential.

\section{Comparison with other risk score}

Janwantanakul et al. [23] constructed a screening tool based on the previous history of LBP and psychological demand (assessed by the Job Content Questionnaire) with a good AUC of 0.76 (95\% CI 


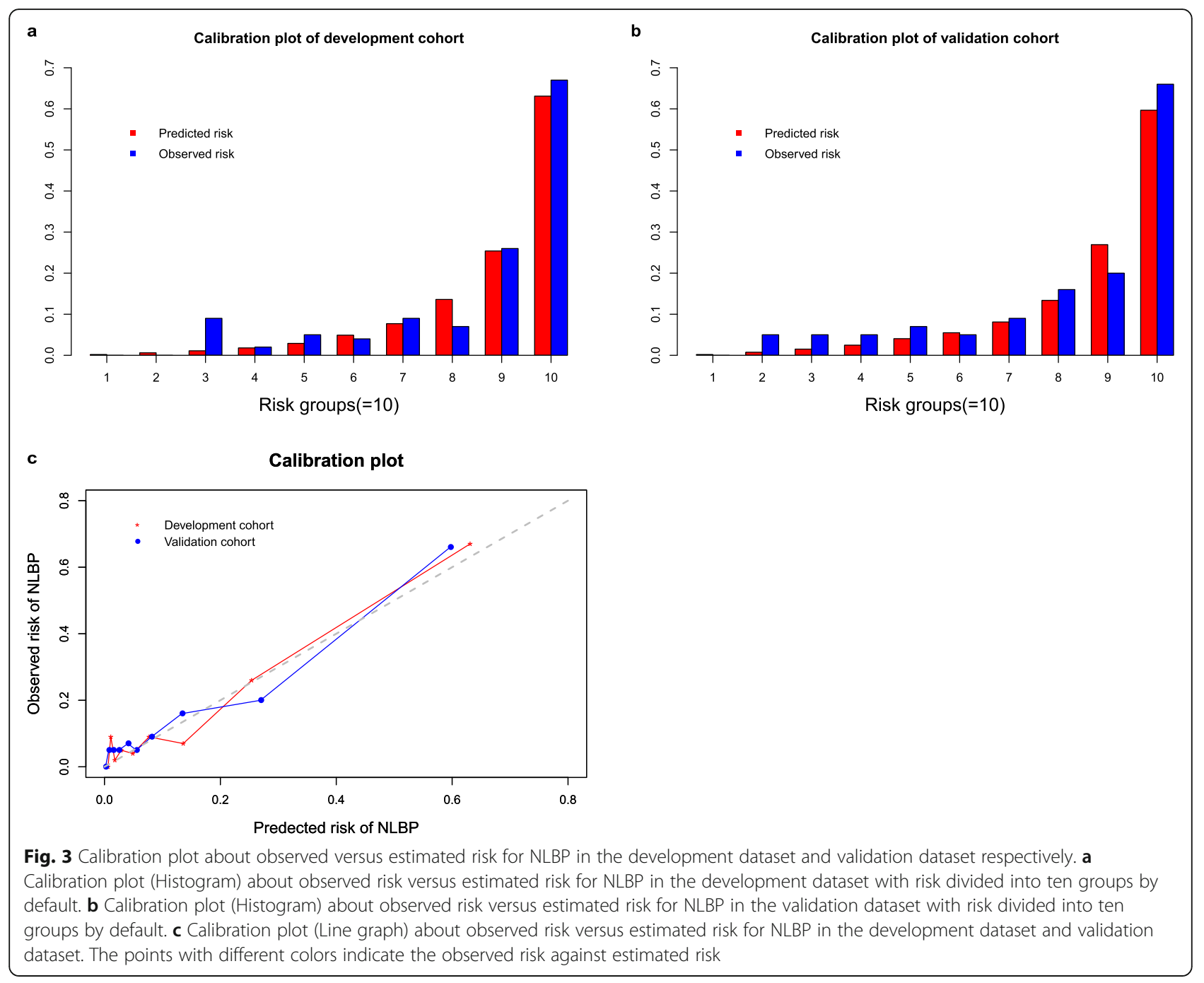

0.68-0.83). Jensen et al. [28] used baseline clinical and psychosocial risk factors to predict patients with low, intermediate and high risk for an unsuccessful return to work, both initially and at 1-year, and yielded an excellent predictive effect. However, our pre-scoring system was developed among the general population whose population characteristic and risk exposure were different from those mentioned above. The AUC of the proposed system reached 0.821 in the validation dataset, demonstrating its excellent discrimination in the general population.

\section{Strengths and limitations}

In this manuscript, our system enjoys the following properties: (1) It included a relatively large number of participants; (2) EM imputation was applied to utilize information as much as possible and ensuringd the robustness of the results; (3) the pre-scoring system was of high discriminating power as well as high stability.

Our study has several limitations as follows. First, it is not well suited to establish the causal relationship between exposure factors and outcome with a cross-sectional study. Therefore, the system in this

Table 5 Risk grades of NLBP

\begin{tabular}{|c|c|c|c|c|c|c|}
\hline \multirow[t]{2}{*}{ Risk category } & \multicolumn{3}{|c|}{ Development Dataset, $N=1002$} & \multicolumn{3}{|c|}{ Validation Dataset, $N=437$} \\
\hline & Participants (n) & Incidence, n (\%) & Odds Ratio $(95 \%$ Cl) & Participants (n) & Incidence, n (\%) & Odds Ratio $(95 \%$ Cl) \\
\hline Low-risk (0-18 score) & 688 & $29(4.3)$ & 1.0 & 298 & $15(5.0)$ & 1.0 \\
\hline Intermediate-risk (19-22 score) & 210 & $31(14.8)$ & $3.9(2.3-6.7)$ & 97 & $15(15.5)$ & $3.5(1.6-7.4)$ \\
\hline High-risk (23-38 score) & 104 & $70(67.3)$ & $46.8(26.9-81.4)$ & 42 & $28(66.7)$ & $37.7(16.5-86.1)$ \\
\hline
\end{tabular}


study should be taken as a preliminary result. Secondly, there might be a bias if the findings are applied outside Guangzhou. Thirdly, we overlooked some potential risk factors in rehabilitation medicine or physical therapy (such as muscle imbalance) that may introduce some bias in our result. While some studies indicated that exercise could reduce muscle imbalance $[49,50]$, which stated that exercise, an essential variable in our model, is likely to explain the partial effects of muscle imbalance on NLBP. Finally, the bootstrap procedure, based on the developed risk score and did not include the variable selection step, might lead to the estimated bias of over-optimism in a way.

\section{Conclusions}

We validated a pre-scoring system based on eight demographic and work-related features and two psychosocial factors that may be useful for assessing the risk of NLBP among the general population in Guangzhou.

\section{Additional file}

Additional file 1: Excel S1 A Scoring System for Nonspecific LBP among the general Population in Guangzhou. (XLSX 25 kb)

\section{Abbreviations \\ AUC: Area under the curve; BMI: Body mass index; EM: Expectation- maximum; EPV: Events per variable; IDI: Integrated discrimination improvement; LBP: Low back pain; NLBP: Nonspecific low back pain; NRI: Net reclassification improvement; ROC: Receiver operating characteristics curve; TRIPOD: Transparent reporting of a multivariable prediction model for individual prognosis or diagnosis}

\section{Acknowledgements}

We would like to thank Prof. Rangke Wu from Southern Medical University, Guangzhou, China, for his polishing and proofreading this English manuscript.

\section{Authors' contributions}

SLA and SXM conceived and designed the study. XYX and KW collected the data. KW analyzed the data. KW and JWZ drafted the manuscript. SLA, SXM and KW reviewed/consulted the manuscript; SLA, KW, SXM and JWZ contributed to the critical revision of the manuscript. All authors commented on drafts and read and approved the final manuscript.

\section{Funding}

This study was supported by Grant from School of Public Health of Southern Medical University, China (GW201421).

\section{Availability of data and materials}

The datasets used and/or analyzed during the current study are available from the corresponding author on reasonable request.

\section{Ethics approval and consent to participate}

The study protocol was approved by the Institutional Review Board at Zhujiang Hospital, Southern Medical University, Guangzhou, China (NO.2013BLK-009). Written informed consent was obtained from all participants for entry into the database and use of their data for research.

\section{Consent for publication}

Not applicable.

\section{Competing interests}

The authors declare that they have no competing interests.

\section{Author details}

'Department of Biostatistics, School of Public Health (Guangdong Provincial Key Laboratory of Tropical Disease Research), Southern Medical University, No. 1838 North Guangzhou Avenue, Guangzhou 510515, People's Republic of China. ${ }^{2}$ Department of Epidemiology and Biostatistics, School of Public Health, Tongji Medical College, Huazhong University of Science and Technology, No. 13 Hangkong Road, Wuhan 430030, People's Republic of China. ${ }^{3}$ Orthopaedic Center, Zhujiang Hospital, Southern Medical University, No. 253 Gongye Avenue, Guangzhou 510282, People's Republic of China.

Received: 4 March 2019 Accepted: 28 August 2019

Published online: 12 September 2019

\section{References}

1. UK NCCF. Low back pain: early management of persistent non-specific low back pain. London: Royal College of General Practitioners (UK); 2009.

2. Berman BM, Langevin HM, Witt CM, Dubner R. Acupuncture for chronic low back pain. N Engl J Med. 2010;363(5):454-61.

3. Kuiper Jl, Burdorf A, Frings-Dresen MH, Kuijer PP, Spreeuwers D. Assessing the work-relatedness of nonspecific low-back pain. Scand J Work Environ Health. 2005;31(3):237-43.

4. Lizier DT, Perez MV, Sakata RK. Exercises for treatment of nonspecific low back pain. Rev Bras Anestesiol. 2012;62(6):838-46.

5. Shiri R, Solovieva S, Husgafvel-Pursiainen K, Viikari J, Raitakari OT, ViikariJuntura E. Incidence of nonspecific and radiating low back pain: follow-up of 24-39-year-old adults of the young finns study. Arthritis Care Res (Hoboken). 2010;62(4):455-9.

6. Yao W, Luo C, Ai F, Chen Q. Risk factors for nonspecific low-back pain in Chinese adolescents: a case-control study. Pain Med. 2012;13(5):658-64.

7. Akdag B, Cavlak U, Cimbiz A, Camdeviren H. Determination of pain intensity risk factors among school children with nonspecific low back pain. Med Sci Monit. 2011;17(2):H12-5.

8. Menezes Costa LDC, Added MAN, Costa LOP, Fukuda TY, de Freitas DG, Salomão EC, et al. Efficacy of adding the kinesio taping method to guideline-endorsed conventional physiotherapy in patients with chronic nonspecific low back pain: a randomized controlled trial. BMC Musculoskelet Disord. 2013;14(1):301-9.

9. Hurwitz EL, Morgenstern H, Chiao C. Effects of recreational physical activity and back exercises on low back pain and psychological distress: findings from the UCLA low back pain study. Am J Public Health. 2005;95(10):1817-24.

10. Froud R, Patterson S, Eldridge S, Seale C, Pincus T. A systematic review and meta-synthesis of the impact of low back pain on people's lives. BMC Musculoskelet Disord. 2014;15(1):50-64.

11. Krismer M, van Tulder M. Strategies for prevention and management of musculoskeletal conditions. Low back pain (non-specific). Best Pract Res Clin Rheumatol. 2007; 1 (1):77-91.

12. Wang YX, Wang JQ, Kaplar Z. Increased low back pain prevalence in females than in males after menopause age: evidences based on synthetic literature review. Quant Imaging Med Surg. 2016;6(2):199-206.

13. Silva MR, Badaro AF, Dall'Agnol MM. Low back pain in adolescent and associated factors: a cross sectional study with schoolchildren. Braz J Phys Ther. 2014;18(5):402-9.

14. Secer M, Nacar OA, Muradov MJ, Altintoprak F, Kabali B, Senol Z, et al. Nonspecific low back pain in a group of young adult men. Turk Neurosurg. 2011;21(2):135-9.

15. Lis AM, Black KM, Korn H, Nordin M. Association between sitting and occupational LBP. Eur Spine J. 2007;16(2):283-98.

16. Gremeaux V, Casillas J, Fabbro-Peray P, Pelissier J, Herisson C, Perennou D. Analysis of low back pain in adults with scoliosis. Spine. 2008;33(4):402-5.

17. Hamberg-van RH, Ariens GA, Blatter BM, Twisk JW, van Mechelen W, Bongers PM. Physical capacity in relation to low back, neck, or shoulder pain in a working population. Occup Environ Med. 2006;63(6):371-7.

18. Adams MA, Mannion AF, Dolan P. Personal risk factors for first-time low back pain. Spine. 1999;24(23):2497-505.

19. Nadler SF, Malanga GA, Feinberg JH, Prybicien M, Stitik TP, DePrince M. Relationship between hip muscle imbalance and occurrence of low back pain in collegiate athletes: a prospective study. Am J Phys Med Rehabil. 2001;80(8):572-7. 
20. Lee JH, Hoshino Y, Nakamura K, Kariya Y, Saita K, Ito K. Trunk muscle weakness as a risk factor for low back pain. A 5-year prospective study. Spine (Phila Pa 1976). 1999;24(1):54-7.

21. Von Korff M, Miglioretti DL. A prognostic approach to defining chronic pain. Pain. 2005;117(3):304-13.

22. Hill JC, Dunn KM, Lewis M, Mullis R, Main CJ, Foster NE, et al. A primary care back pain screening tool: identifying patient subgroups for initial treatment. Arthritis Rheum. 2008;59(5):632-41.

23. Janwantanakul P, Sihawong R, Sitthipornvorakul E, Paksaichol A. A screening tool for non-specific low back pain with disability in office workers: a 1-year prospective cohort study. BMC Musculoskelet Disord. 2015;16(1):298-306.

24. Parsaeian M, Mohammad K, Mahmoudi M, Zeraati H. Comparison of logistic regression and artificial neural network in low back pain prediction: second national health survey. Iran J Public Health. 2012;41(6):86-92.

25. Mendelek F, Caby I, Pelayo P, Kheir RB. The application of a classificationtree model for predicting low back pain prevalence among hospital staff. Arch Environ Occup Health. 2013;68(3):135-44.

26. Shehab DK, Al-Jarallah KF. Nonspecific low-back pain in kuwaiti children and adolescents: associated factors. J Adolesc Health. 2005;36(1):32-5.

27. Campbell P, Wynne-Jones G, Muller S, Dunn KM. The influence of employment social support for risk and prognosis in nonspecific back pain: a systematic review and critical synthesis. Int Arch Occup Environ Health. 2013:86(2):119-37.

28. Jensen OK, Stengaard-Pedersen K, Jensen C, Nielsen CV. Prediction model for unsuccessful return to work after hospital-based intervention in low back pain patients. BMC Musculoskelet Disord. 2013;14(1):140-56.

29. Kuorinka I, Jonsson B, Kilbom A, Vinterberg H, Rensen FB. Standardised Nordic questionnaires for the analysis of musculoskeletal symptoms. Appl Ergon. 1987;18(3):233-7.

30. Janwantanakul P, Pensri P, Moolkay P, Jiamjarasrangsi W. Development of a risk score for low back pain in office workers--a cross-sectional study. BMC Musculoskelet Disord. 2011;12(1):23-31.

31. Peduzzi P, Concato J, Feinstein AR, Holford TR. Importance of events per independent variable in proportional hazards regression analysis. II. Accuracy and precision of regression estimates. J Clin Epidemiol. 1995;48(12):1503-10.

32. Harrell FJ, Lee KL, Mark DB. Multivariable prognostic models: issues in developing models, evaluating assumptions and adequacy, and measuring and reducing errors. Stat Med. 1996;15(4):361-87.

33. Pencina MJ, D'Agostino RS, D'Agostino RJ, Vasan RS. Evaluating the added predictive ability of a new marker: from area under the ROC curve to reclassification and beyond. Stat Med. 2008;27(2):157-72 207-12.

34. Sullivan LM, Massaro JM, D'Agostino RB Sr. Presentation of multivariate data for clinical use: the Framingham study risk score functions. Stat Med. 2004;23(10):1631-60

35. Collins GS, Reitsma JB, Altman DG, Moons KG. Transparent reporting of a multivariable prediction model for individual prognosis or diagnosis (TRIPOD): the TRIPOD statement. Br J Surg. 2015;102(3):148-58.

36. Dagenais S, Caro J, Haldeman S. A systematic review of low back pain cost of illness studies in the United States and internationally. Spine J. 2008:8(1):8-20.

37. Vibe FK, O'Sullivan P, Skouen JS, Smith A, Kvale A. Efficacy of classificationbased cognitive functional therapy in patients with non-specific chronic low back pain: a randomized controlled trial. Eur J Pain. 2013;17(6):916-28.

38. Yue P, Liu F, Li L. Neck/shoulder pain and low back pain among school teachers in China, prevalence and risk factors. BMC Public Health. 2012;12(1):789-97.

39. De Cocker K, Duncan MJ, Short C, van Uffelen JG, Vandelanotte C. Understanding occupational sitting: prevalence, correlates and moderating effects in Australian employees. Prev Med. 2014;67(10):288-94.

40. Hadgraft NT, Lynch BM, Clark BK, Healy GN, Owen N, Dunstan DW. Excessive sitting at work and at home: correlates of occupational sitting and TV viewing time in working adults. BMC Public Health. 2015;15(1):899-912.

41. Vandelanotte C, Duncan MJ, Short C, Rockloff M, Ronan K, Happell B, et al. Associations between occupational indicators and total, work-based and leisuretime sitting: a cross-sectional study. BMC Public Health. 2013;13(12):1110-8.

42. Wallmann-Sperlich B, Bucksch J, Schneider S, Froboese I. Sociodemographic, behavioural and cognitive correlates of work-related sitting time in German men and women. BMC Public Health. 2014;14(1):1259-69.

43. Sjolie AN. Persistence and change in nonspecific low back pain among adolescents: a 3-year prospective study. Spine. 2004;29(21):2452-7.

44. Corlett EN. Background to sitting at work: research-based requirements for the design of work seats. Ergonomics. 2006;49(14):1538-46.
45. Hoy D, Brooks P, Blyth F, Buchbinder R. The epidemiology of low back pain. Best Pract Res Clin Rheumatol. 2010;24(6):769-81.

46. Karunanayake AL, Pathmeswaran A, Kasturiratne A, Wijeyaratne LS. Risk factors for chronic low back pain in a sample of suburban Sri Lankan adult males. Int J Rheum Dis. 2013;16(2):203-10.

47. Kheterpal S, Tremper KK, Heung M, Rosenberg AL, Englesbe M, Shanks AM, et al. Development and validation of an acute kidney injury risk index for patients undergoing general surgery: results from a national data set. Anesthesiology. 2009;110(3):505-15.

48. Kim MY, Jang HR, Huh W, Kim YG, Kim DJ, Lee YT, et al. Incidence, risk factors, and prediction of acute kidney injury after off-pump coronary artery bypass grafting. Ren Fail. 2011;33(3):316-22.

49. Richmond J. Multi-factorial causative model for back pain management; relating causative factors and mechanisms to injury presentations and designing time- and cost effective treatment thereof. Med Hypotheses. 2012:79(2):232-40.

50. Sorosky S, Stilp S, Akuthota V. Yoga and pilates in the management of low back pain. Curr Rev Musculoskelet Med. 2008;1(1):39-47.

\section{Publisher's Note}

Springer Nature remains neutral with regard to jurisdictional claims in published maps and institutional affiliations.

Ready to submit your research? Choose BMC and benefit from:

- fast, convenient online submission

- thorough peer review by experienced researchers in your field

- rapid publication on acceptance

- support for research data, including large and complex data types

- gold Open Access which fosters wider collaboration and increased citations

- maximum visibility for your research: over $100 \mathrm{M}$ website views per year

At BMC, research is always in progress.

Learn more biomedcentral.com/submissions 